Original Article

\title{
PRETREATMENT VARIATIONS IN HAEMATOLOGICAL PARAMETERS OF BREAST CANCER PATIENTS
}

\author{
ABDULLATIF ABDULAZIZ AL-ARIFI' ${ }^{1}$, ASHOK KUMAR ${ }^{2}$, SRIDEVI CHIGURUPATI ${ }^{3}$, MUHAMMAD JAWED ${ }^{4}$, THUNGA \\ PANDURANGAN 5
}

${ }^{1}$ College of Medicine, King Faisal University, Al Ahsa, Kingdom of Saudi Arabia, ${ }^{2}$ Department of Pathology, Faculty of Medicine, AIMST University, Semeling, Kedah, Malaysia, ${ }^{3}$ Department of Pharmaceutical Chemistry, Faculty of Pharmacy, AIMST University, Semeling, Kedah, Malaysia, ${ }^{4}$ Sindh Institute of Ophthalmology and Visual Science, Hyderabad, ${ }^{5}$ Department of Surgery, Faculty of Medicine, AIMST University, Semeling, Kedah, Malaysia Email: dr.ashok.kumar@hotmail.com

Received: 14 Nov 2017 Revised and Accepted: 03 Jan 2018

\section{ABSTRACT}

Objective: The objective of the presented study was to analyze the haematological parameters in female breast cancer (BC) patients before the start of the treatment.

Methods: The study was conducted among female BC patients, visited King Fahd Hospital (KFH), Al Ahsa, Kingdom of Saudi Arabia (KSA) from January 2013 to December 2016. A retrospective analytical study was conducted. We analyzed the relationship of haematological parameters with various stages of breast cancer before the start of any treatment. We used complete blood count (CBC) reports to analyze the haematological parameters. The mean age of the patients was $57 \mathrm{y}$ (31-83 y). Most of the patients were postmenopausal (51-59 y old). We divided the patients into 4 groups according to the disease stage, i.e., stage 1 (S1) to stage 4 (S4).

Results: Among altered blood parameters, decreased haemoglobin (Hb 4.5-11 g/dl) and increased erythrocyte sedimentation rate (ESR 37-49 $\mathrm{mm}$ /first hour) in S1 to S4, increased neutrophil count in S3 and S4 (8.3-9.6 x10 $\left./ \mathrm{mm}^{3}\right)$, and increased lymphocyte count (4-7.2 x103/mm $\left.{ }^{3}\right)$ in S1 and S2 patients were found.

Conclusion: We found significant variations in haematological parameters at different stages of breast cancer. CBC is indeed an efficient and costeffective investigation. By managing these parameters, treatment efficacy and survival rate of BC patients may be augmented.

Keywords: Breast cancer, Haemoglobin, Erythrocyte sedimentation rate, Neutrophilia, Lymphocytosis

(c) 2018 The Authors. Published by Innovare Academic Sciences Pvt Ltd. This is an open access article under the CC BY license (http://creativecommons.org/licenses/by/4.0/) DOI: http://dx.doi.org/10.22159/ijpps.2018v10i2.23669

\section{INTRODUCTION}

Breast cancer (BC) has frequently displayed a high influence towards the health of females globally including the Kingdom of Saudi Arabia (KSA). Every year, more than 1.4 million new cases of BC are diagnosed. It has been described to be the most common cancer and the leading cause of cancer mortality in females. Cancer itself conveys remarkable emotional, social, economic, and public health consequences [1]. The incidence rates of $\mathrm{BC}$ in females of the Arab world have increased in the last $24 \mathrm{y}$; with an increase in the number of females being diagnosed with advanced stages of this cancer [2]. It has been reported that through the early detection of BC by means of screening activities, the morbidity and mortality rates have been successfully reduced $[3,4]$. Regardless of these results, Arab females showed low participation in BC screening activities [5]. An elaborated data has been reported on BC in Western countries and developed nations, but in the KSA it seems either scattered or not brought to attention [6]. Clinically, early BC patients usually do not present with the complaint of pain. When the malignancy grows, it causes alterations in the shape or size of the breast. In many cases, a mass may be noticed by the patient in the affected breast. In progressive cases, the malignancy may display the signs of fixation to the chest wall and the ulcerations of the skin. Large lymph nodes may be present in severe cases $[7,8]$. If one of these symptoms appears a suitable investigation such as, ultrasonography or tissue biopsy should be implemented to diagnose the disease at early stages [9-11]. In addition to these investigations, complete blood count (CBC) has its own significance. It provides information on haematological parameters such as morphologies and counts of red blood cells (RBCs), white blood cells (WBCs), platelets, and the erythrocyte sedimentation rate (ESR). It is indeed an essential and cost-effective investigation demanded from all patients with malignancy before the use of chemotherapy, radiotherapy and surgery. Many studies have shown the adverse outcome of malignancies in the patients who have poor haematological parameters. The $\mathrm{Hb}[12,13]$, ESR level [14], and the white blood cell (WBC) counts, including full and differential [1517], predict the severity and mortality risk of cancer patients. Platelet count aids to monitor the progress of cancer. Cancer cells secret procoagulants and inflammatory cytokines which trigger the activation of the coagulation system and consumption of platelets, resulting in multiple organ failure and death [18]. Thus, CBC helps a health care professional to further investigate any underlying pathology and treat accordingly. Every kind of disease that varies in terms of disease progression has, in fact, a direct influence towards haematological parameters. Breast cancer likewise has its effects on these parameters [19]. Hence, it is essential to study the haematological parameters in $\mathrm{BC}$ patients before, during and after the onset of treatment. In the current study, we analyzed the haematological parameters of BC patients before the start of the treatment.

\section{MATERIALS AND METHODS}

The study was conducted among female BC patients, visited King Fahd Hospital (KFH), Al Ahsa from January 2013 to December 2016. We obtained the approval from the institutional review board of $\mathrm{KFH}, \mathrm{Al}$ Ahsa, KSA (Notary verified letter reference no: 2270204). We conducted a retrospective study on haematological parameters by interpreting the results of CBC and ESR and analyzed their associations with various stages of breast cancer before the start of chemotherapy, radiotherapy, or surgery. The medical records and haematological parameters of 100 female BC patients were retrieved and analyzed. The mean age of the patients was $57 \mathrm{y}(31-83 \mathrm{y})$. Most of the patients (92) were postmenopausal (51-59 y old). We divided the patients into four groups according to the disease stage, i.e., stage 1 (S1), stage 2 (S2), stage 3 (S3) 
and stage 4 (S4). The haematological parameters included haemoglobin $(\mathrm{Hb})$, mean corpuscular volume (MCV), erythrocyte sedimentation rate (ESR), platelet count (PC), total leucocyte count (TLC), and differential leucocyte count (DLC) i.e., absolute counts of neutrophils, lymphocytes, monocytes, eosinophils and basophils.

\section{Statistical analysis}

The data were analyzed using SPSS version 16 . The patients were presented as the number and the percentage in each stage of the disease. The haematological parameters were presented as mean \pm standard deviation (SD).

\section{RESULTS}

Among total 100 patients, 40 were in S1, 36 in S2, 18 in S3 and 6 in S4. The staging was done by the consultant oncologists and pathologists of the hospital as per the standard guidelines, described [20]. Among these patients, anaemia (low $\mathrm{Hb}$ level) was found in the following number and percentage of patients in each individual group. 9 patients $(22.5 \%)$ in $\mathrm{S} 1$,
5 patients (13.88\%) in S2, 5 patients $(27.77 \%)$ in S3 and 3 patients $(50 \%)$ in S4. The anaemia was mild ( $\mathrm{Hb} 8-11 \mathrm{~g} / \mathrm{dl})$ in S1, S2 and S3 patients, while moderate to severe $(\mathrm{Hb} 4.5-7.5 \mathrm{~g} / \mathrm{dl})$ in $\mathrm{S} 4$ patients (normal $\mathrm{Hb} 12-16 \mathrm{~g} / \mathrm{dl}$ ). Fig. 1 shows the level of haemoglobin and the percentage of anaemic patients in each disease stage. Morphologically, the RBCs were normocytic normochromic with the MCV 81-96 fl (normal 80-100 fl). The ESR remained moderately raised (37-49 $\mathrm{mm} /$ first hour) (normal $<20 \mathrm{~mm} /$ first hour) in almost all (98) patients (fig. 2). The total leukocyte count (TLC) remained under normal range $\left(4-11 \times 10^{3} / \mathrm{mm}^{3}\right)$ in all patients; but, absolute neutrophil count was found to be raised $\left(8.3-9.6 \times 10^{3} / \mathrm{mm}^{3}\right.$ ) (normal $2.5-7.5 \times 10^{3} / \mathrm{mm}^{3}$ ) in 5 patients (27.77\%) of S3 and 2 patients (33.33\%) of S4 (fig. 3). These two neutrophilic patients from S4 had concomitant severe anaemia. Absolute lymphocyte count was found to be raised (4-7.2 $\mathrm{x} 10^{3} / \mathrm{mm}^{3}$ ) (normal 1.5$3.5 \times 10^{3} / \mathrm{mm}^{3}$ ) in 16 patients (40\%) of S1 and 5 patients (13.88\%) of S2 (fig. 4). All these results are summed up in table 1. Other differential (monocyte, eosinophil and basophil) and platelet counts were within normal range. The normal laboratory values of the haematological parameters have been described [21].

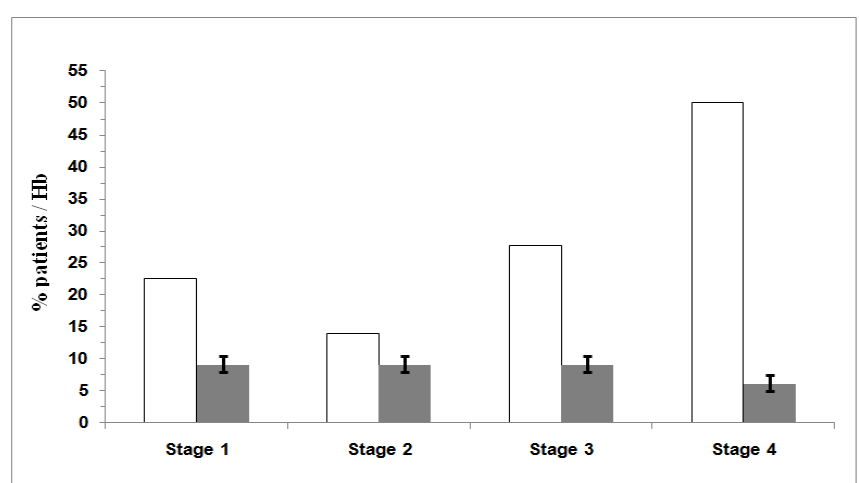

Fig. 1: Anaemic patients with $\mathrm{Hb}$ level. $\square \%$ of patients in individual stage. $\square \mathrm{Hb}(\mathrm{g} / \mathrm{dl}) . \mathrm{Hb}$ is presented as mean \pm standard deviation (SD). Normal Hb level: 12-16 g/dl. Total number of patients $(n=100)$

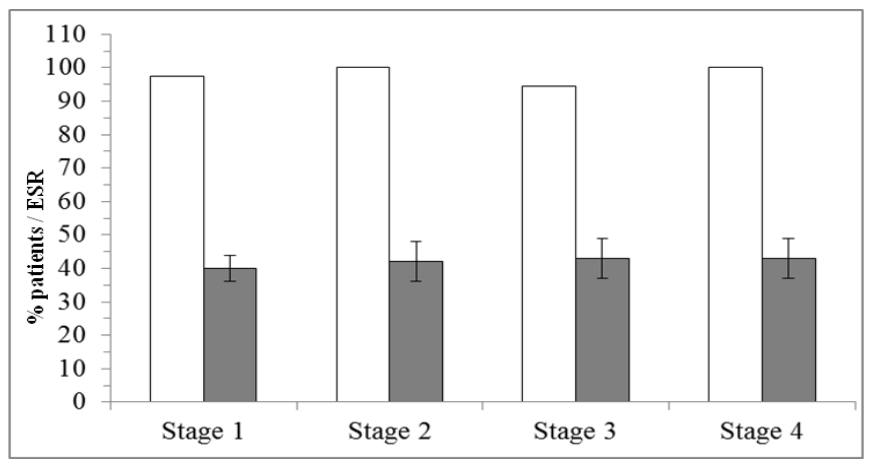

Fig. 2: Patients with raised ESR. $\square \%$ of patients in individual stage. $\square$ ESR $(\mathrm{mm} /$ fisrt $\mathrm{h})$. ESR is presented as mean \pm standard deviation (SD). Normal ESR level: $<20 \mathrm{~mm} /$ first $h$, total number of patients $(\mathrm{n}=100)$

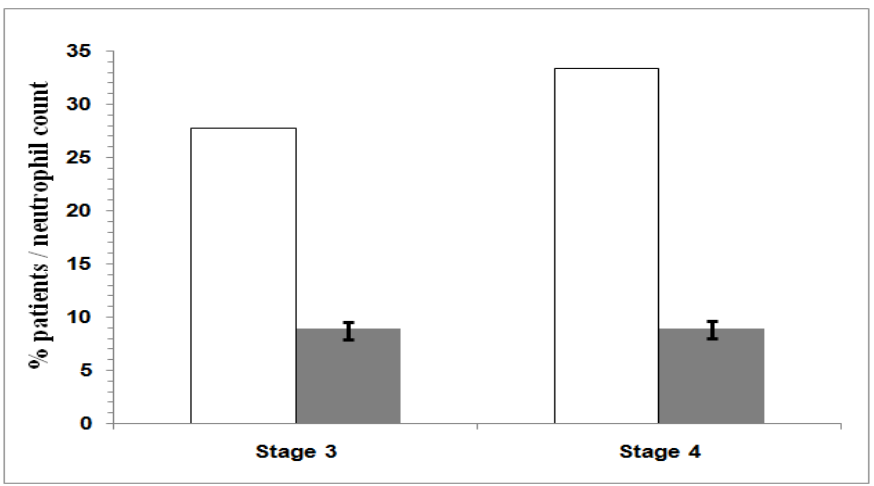

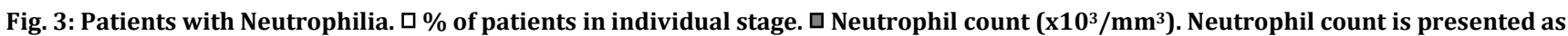
mean \pm standard deviation (SD). Normal neutrophil count: $2.5-7.5 \times 10^{3} / \mathrm{mm}^{3}$. Total number of patients $(\mathrm{n}=100)$ 


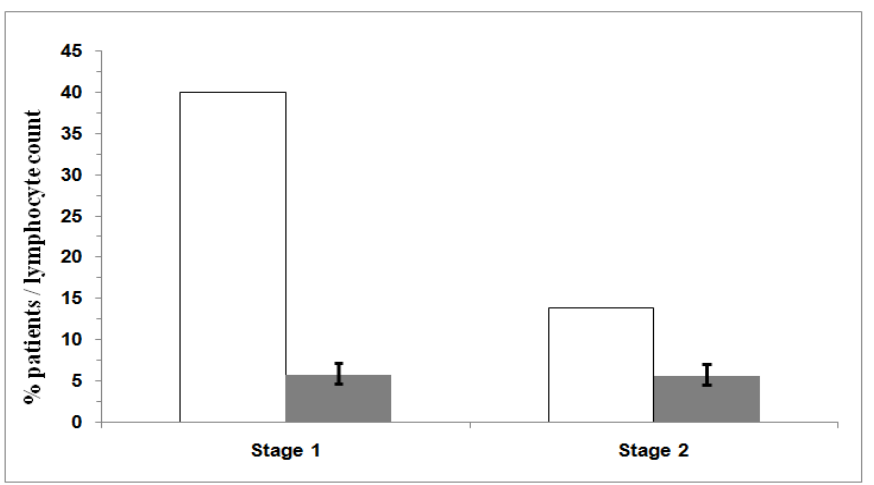

Fig. 4: Patients with lymphocytosis. $\square \%$ of patients in individual stage. $\square$ Lymphocyte count $\left(\mathrm{x}^{3} \mathrm{o}^{3} / \mathrm{mm}^{3}\right)$. Lymphocyte count is presented as mean \pm standard deviation (SD), Normal lymphocyte count: $1.5-3.5 \times 10^{3} / \mathrm{mm}^{3}$. Total number of patients $(\mathrm{n}=100)$

Table 1: Haematological parameters of breast cancer patients

\begin{tabular}{|c|c|c|c|c|c|}
\hline Breast cancer stage & Normal & Stage 1 & Stage 2 & Stage 3 & Stage 4 \\
\hline $\mathrm{Hb}(\mathrm{g} / \mathrm{dl})($ mean $\pm \mathrm{SD})$ & $14 \pm 2$ & $9.5 \pm 1.5$ & $9.5 \pm 1.5$ & $9.5 \pm 1.5$ & $6 \pm 1.5$ \\
\hline No. of patients & & 9 out of 40 & 5 out of 36 & 5 out of 18 & 3 out of 6 \\
\hline$\%$ of patients & & $22.50 \%$ & $13.88 \%$ & $27.77 \%$ & $50 \%$ \\
\hline $\operatorname{ESR}(\mathrm{mm} /$ first $\mathrm{h})($ mean $\pm \mathrm{SD})$ & $10 \pm 10$ & $40 \pm 4$ & $42 \pm 6$ & $43 \pm 6$ & $43 \pm 6$ \\
\hline No. of patients & & 39 out of 40 & 36 out of 36 & 17 out of 18 & 6 out of 6 \\
\hline$\%$ of patients & & $97.50 \%$ & $100 \%$ & $94.40 \%$ & $100 \%$ \\
\hline Neutrophil count $\left(\mathrm{x} 10^{3} / \mathrm{mm}^{3}\right)($ mean $\pm \mathrm{SD})$ & $5 \pm 2.5$ & $5 \pm 2.5$ & $5 \pm 2.5$ & $8.95 \pm 0.65$ & $8.95 \pm 0.65$ \\
\hline No. of patients & & 40 out of 40 & 36 out of 36 & 5 out of 18 & 2 out of 6 \\
\hline$\%$ of patients & & $100 \%$ & $100 \%$ & $27.77 \%$ & $33.33 \%$ \\
\hline Lymphocyte count $\left(\mathrm{x} 10^{3} / \mathrm{mm}^{3}\right)($ mean \pm SD $)$ & $2.5 \pm 1$ & $5.7 \pm 1.5$ & $5.5 \pm 1.5$ & $2.5 \pm 1$ & $2.5 \pm 1$ \\
\hline No. of patients & & 16 out of 40 & 5 out of 36 & 18 out of 18 & 6 out of 6 \\
\hline$\%$ of patients & & $40 \%$ & $13.88 \%$ & $100 \%$ & $100 \%$ \\
\hline
\end{tabular}

Total number of patients $(\mathrm{n}=100)$. The above parameters are expressed in: $\mathrm{Hb}(\mathrm{g} / \mathrm{dl})$, ESR (mm/first hr), Neutrophil count (x10³/mm $\left.{ }^{3}\right)$, Lymphocyte count $\left(\mathrm{x} 10^{3} / \mathrm{mm}^{3}\right)$.

\section{DISCUSSION}

Complete blood count (CBC) is a basic and an essential investigation for any disease prior to the treatment. Through this investigation, various haematological parameters are measured. Alterations in any of those may further help investigate the underlying potential causes and treat them accordingly. Hence, it helps to improve the general health, immunity and tolerance of the patient to the treatment. Likewise, it is an important investigation for breast cancer (BC) patients prior to the start of any treatment, i.e., chemotherapy, radiotherapy or surgery. In the current study, we analyzed the haematological parameters of the female BC patients. We found significant variations in their haematological parameters. Around $1 / 4$ (22\%) of the total BC patients were found to have decreased $\mathrm{Hb}$ levels. The patients showed normocytic normochromic anaemia. Our results significantly correlate with a previous study conducted in India, which showed decreased $\mathrm{Hb}$ level in more than $60 \%$ of breast cancer patients. Those patients also displayed normocytic normochromic anaemia [22]. As India is a heavily populated country with poor socio-economic conditions, decreased $\mathrm{Hb}$ level in the majority of these patients could be due to nutritional deficiencies [23]. Contrary to that, KSA people have a good nutritional and a higher socio-economic condition, hence less number of patients were anaemic, which may have resulted from various factors, such as, cytokine secretion by tumor cells, or decreased production of erythropoietin. Based on previous reports, it was shown that chronic diseases and cancers could cause decreased levels of erythropoietin, leading to decreased production of RBCs with resulting anaemia [24]. The other possible cause of anaemia in our patients might be the metastasis of cancer cells to bone marrow, which seems less likely as it would have also caused the suppression of other haematological series. In addition to this, stage 1 patients also were anaemic in which there is no metastasis. Nevertheless, the metastasis in the initial stages cannot be completely ruled out. Haematopoiesis suppression due to metastasis of breast cancer cells to bone marrow has already been described $[25,26]$. On the other hand, low $\mathrm{Hb}$ level has been shown to cause poorer oxygenation of tumor cells, which could activate the metastatic genes, leading to the metastasis and resistance of cancer cells to chemo and radiotherapy, resulting in the worse survival of $\mathrm{BC}$ patients [12-13]. Hence, $\mathrm{Hb}$ is an important parameter, which may be improved in these patients, for example through the exogenous administration of erythropoietin [27]. Furthermore, we found a significant raise in ESR in almost all BC patients. Increased ESR has been found in many malignant diseases including breast cancer and several inflammatory disorders [28], and has been frequently associated with a much poorer prognosis $[14,28]$.

Total leucocyte count (TLC) on the other hand was normal in our patients, but the absolute neutrophil count was found to be raised in S3 and S4 patients. Previously, Rana AP and his team of medical experts reported increased neutrophil count in advanced stages of BC patients [22]. The increase in neutrophil count may indicate various conditions, such as bacterial infection [29], or increased cytokine release by cancer cells, which helps them disseminate to other sites [30,31]. Previous reports have shown that increased neutrophil count is often associated with poor prognosis of breast and other cancers $[15,16]$.

Absolute lymphocyte count was found to be slightly raised in our S1 and S2 BC patients. Our results correlate with two other studies which showed increased lymphocyte count in the early stage of BC patients $[22,31]$. Increased lymphocyte count may be indicative of a good prognosis as it was reported to favor the survival of BC patients [32, 33]. Increased lymphocyte count has also been reported in other cancers such as gastric and head and neck carcinomas [34]. Lymphocytes, specifically CD8+cells and natural killer (NK) cells, are known to play an anti-tumorigenic role in many cancers. NK cells kill the tumor cells without any prior sensitization. Lee and his group reported that even the BC patients with advanced stage who had higher lymphocyte count had a better prognosis than 
the patients with lower lymphocyte count [17]. Nonetheless, many breast cancer cells down-regulate the expression of their surface antigens, specifically class 1 major histocompatibility complex (MHC-I), thus evading the recognition by immune cells [17, 35]. In such situations, the lymphocyte count may remain under normal range. In contrast, it has also been shown that if MHC antigens are down regulated to avoid $\mathrm{T}$ cell recognition, they become susceptible to be invaded by NK cells, another type of lymphocytes [36]. Thus, depending upon the cancer cell antigen expressions and immune response, the lymphocyte count may be elevated, or may remain within normal range. Hence, absolute counts of WBCs also provide with the significant information towards managing the disease.

\section{CONCLUSION}

We found significant variations in haematological parameters, which differed considerably at various stages of our breast cancer patients. Decreased $\mathrm{Hb}$ and increased ESR at S1 to S4, increased neutrophil count at S3 and S4, and increased lymphocyte count at S1 and S2 were found. Hence, these parameters have their own significance which provides with the essential information from very basic to advanced disease processes. By managing these parameters, patients' treatment response and survival rate may be significantly augmented.

\section{Study limitation}

In our study, the number of patients was limited to 100 , which was further divided into four groups according to the disease stage.

\section{ACKNOWLEDGEMENT}

Authors are thankful to the directorate and the technical staff of King Fahad Hospital Al Ahsa to support and assist in accessing and collecting the data of this study.

\section{AUTHORS CONTRIBUTIONS}

I declare that this work was done by the authors named in this article and all liabilities pertaining to claims relating to the content of this article will be borne by the authors. Dr. Abdullatif Abdulaziz Al-Arifi collected the data and wrote the introduction part. Dr. Sridevi Chigurupati, Dr. Muhammad Jawed and Prof. Dr. Thunga Pandurangan analyzed the data and wrote the material and method, result and abstract parts. Dr. Ashok Kumar designed the study, wrote the discussion part and proof-read the whole manuscript.

\section{CONFLICT OF INTERESTS}

Declared none

\section{REFERENCES}

1. Brown R, Kerr K, Haoudi A, Darzi A. Tackling cancer burden in the Middle East: Qatar as an example. Lancet Oncol 2012; 13:e501-8.

2. Radi SM. Breast cancer awareness among Saudi females in Jeddah. Asian Pac J Cancer Prev 2013;14:4307-12.

3. Baron Epel O, Friedman N, Lernau O. Reducing disparities in mammography-use in a multicultural population in Israel. Int J Equity Health 2009;19:8-19.

4. Bener A, El Ayoubi HR, Moore MA, Basha B, Joseph S, Chouchane L. Do we need to maximise the breast cancer screening awareness? Experience with an endogamous society with high fertility. Asian Pac J Cancer Prev 2009;4:599-604.

5. Azaiza F, Cohen M, Awad M, Daoud F. Factors associated with low screening for breast cancer in the Palestinian authority. Cancer 2010;116:4646-55.

6. Yousuf SA. Breast cancer awareness among Saudi nursing students. J King Abdulaziz University: Med Sci 2010;17:67-78.

7. Waters EA, McNeel TS, Stevens WM, Freedman AN. Use of tamoxifen and raloxifene for breast cancer chemoprevention in 2010. Breast Cancer Res Treat 2012;134:875-80.

8. Schroyen S, Adam S, Jerusalem G, Missotten P. Ageism and its clinical impact in oncogeriatry: state of knowledge and therapeutic leads. Clin Interventions Agin 2014;10:117-25.

9. Aswathy K Cherian, Poovammal E, Malathy C. Automatic feature extraction for breast density segmentation and classification. Asian J Pharm Clin Res 2017;10:111-5.
10. Elmore JG, Longton GM, Carney PA, Geller BM, Onega T, Tosteson AN, et al. Diagnostic concordance among pathologists interpreting breast biopsy specimens. JAMA 2015;313:1122-32.

11. Shaik Naseera, Gk Rajini, Saravanan M. Statistical detection of breast cancer by mammogram image. Asian J Pharm Clin Res 2017;10:227-9.

12. Gilkes DM. Implications of hypoxia in breast cancer metastasis to bone. Int J Mol Sci 2016;17:1669.

13. Boehm DU, Lebrecht A, Schmidt M, Siggelkow W, Lindner C, Litz A, et al. Prognostic impact of haemoglobin levels in breast cancer. Anticancer Res 2007;27:1223-6.

14. Thynne GS. Plasma carcinoembryonic antigen and erythrocyte sedimentation rate in patients with colorectal carcinoma. Med J Aust 1979;1:592-3.

15. Azab B, Bhatt VR, Phookan J, Murukutla S, Kohn N, Terjanian T, et al. Usefulness of the neutrophil-to-lymphocyte ratio in predicting short-and long-term mortality in breast cancer patients. Ann Surg Oncol 2012;19:217-24.

16. Yamanaka T, Matsumoto S, Teramukai S, Ishiwata R, Nagai $Y$, Fukushima M. The baseline ratio of neutrophils to lymphocytes is associated with patient prognosis in advanced gastric cancer. Oncology 2007;73:215-20.

17. Lee YT. Peripheral lymphocyte count and subpopulations of T and B lymphocytes in benign and malignant diseases. Surg Gynecol Obstet 1977;144:435-50.

18. Caine GJ, Stonelake PS, Lip GY, Kehoe ST. The hypercoagulable state of malignancy: pathogenesis and current debate. Neoplasia 2002;4:465.

19. Ali LO. Study effect of breast cancer on some haematological and biochemical parameters in babylon province, Iraq. IOSRJPBS 2014;9:20-4.

20. Singletary SE, Allred C, Ashley P, Bassett LW, Berry D, Bland KI, et al. Revision of the American joint committee on cancer staging system for breast cancer. J Clin Oncol 2002;20:3628-36.

21. Bain BJ, Bates I, Laffan MA. Dacie and Lewis Practical Hematology E-Book. Elsevier Health Sciences; 2016.

22. Rana AP, Kaur M, Zonunsanga B, Puri A, Kuka AS. Preoperative peripheral blood count in breast carcinoma: a predictor of prognosis or a routine test. Int J Breast Cancer 2015. http://dx.doi.org/10.1155/2015/964392.

23. Akinbami A, Popoola A, Adediran A, Dosunmu A, Oshinaike O, Adebola P, et al. Full blood count pattern of pre-chemotherapy breast cancer patients in Lagos, Nigeria. Caspian J Intern Med 2013;4:574.

24. Poggiali E, De Amicis MM, Motta I. Anemia of chronic disease: a unique defect of iron recycling for many different chronic diseases. Eur J Intern Med 2014;25:12-7.

25. Galasko CS. Skeletal metastases. Clin Orthop Relat Res 1986;210:18-30.

26. Kamby C, Guldhammer B, Vejborg I, Rossing N, Dirksen H, Daugaard S, et al. The presence of tumor cells in bone marrow at the time of the first recurrence of breast cancer. Cancer 1987;60:1306-12.

27. Ludwig H, Fritz E, Leitgeb C, Krainer M, Kührer I, Sagaster P, et al. Erythropoietin treatment for chronic anemia of selected haematological malignancies and solid tumors. Ann Oncol 1993;4:161-7.

28. Bochen K, Krasowska A, Milaniuk S, Kulczynska M, Prystupa A, Dzida G. Erythrocyte sedimentation rate-an old marker with new applications. J Pre-Clin Clin Res 2011;5:50-5.

29. Pfeiler S, Stark K, Massberg S, Engelmann B. Propagation of thrombosis by neutrophils and extracellular nucleosome networks. Haematologica 2017;102:206-13.

30. Dvorak HF. Abnormalities of hemostasis in malignant disease. Hemostasis and Thrombosis. Philadelphia: JB Lippincott; 1994. p. 1238-54.

31. Papatestas AE, Kark AE. Peripheral lymphocyte counts in breast carcinoma: an index of immune competence. Cancer 1974;34:2014-7.

32. Mahmoud SM, Paish EC, Powe DG, Macmillan RD, Grainge $\mathrm{MJ}$, Lee $\mathrm{AH}$, et al. Tumor-infiltrating CD8+lymphocytes predict clinical outcome in breast cancer. J Clin Oncol 2011;29:1949-55. 
33. Liu S, Lachapelle J, Leung S, Gao D, Foulkes WD, Nielsen TO. CD8+lymphocyte infiltration is an independent favourable prognostic indicator in basal-like breast cancer. Breast Cancer Res 2012;14:R48.

34. Ahmad SS, Akhtar K, Verma AK, Mallik AZ, Siddqui SA. Total peripheral lymphocyte count in malignant tumors: an index of prognostication. J Med Sci 2012;12:24-8.
35. Concha A, Cabrera T, Ruiz Cabello F, Garrido F. Can the HLA phenotype be used as a prognostic factor in breast carcinomas? Int J Cancer 1991;47:146-54.

36. Madjd Z, Spendlove I, Pinder SE, Ellis IO, Durrant LG. Total loss of MHC class I is an independent indicator of good prognosis in breast cancer. Int J Cancer 2005;117:248-55. 